\title{
APPLICATION OF NON-DESTRUCTIVE TEST FOR STRUCTURAL HEALTH MONITORING - STATE OF THE ART REVIEW
}

\author{
Darshakkumar.V.Mehta ${ }^{1}$, Mazhar.A.Dhankot ${ }^{2}$ \\ ${ }^{1}$ Research scholar, Marwadi Education Foundation, Gujarat, India \\ ${ }^{2}$ Associate Professor, Civil Engineering Department, Marwadi Education Foundation, Gujarat, India
}

\begin{abstract}
The concept of non-destructive testing (NDT) is to obtain material properties "in place" specimens without the destruction of the specimens and to do the structural health monitoring. NDT using Rebound hammer, Ultra pulse velocity, Half-cell potential, core cutter, carbonation depth, rebar locator, Rapid chloride penetration test, electric resistivity meter test and vibration base analysis by data analoger are very popular and highly effective in conducting structural health monitoring. The structure can be investigated by using a visual inspection, NDT, laboratory and field test performance. In this article a review of these tests have been provided to conduct effective structural health monitoring of a RCC structure
\end{abstract}

Keywords: Non-destructive test, visual inspection, corrosion, compressive strength

\section{INTRODUCTION}

Structural Health Monitoring means the process of implementing a damage detection and characterization strategy for Civil engineering structures like a Buildings, Bridges, tunnels, Dams and reservoirs etc.

Since the beginning of the 20th century, concrete became the main building material for most construction. Studying many buildings made with concrete showed that the concrete can be sensitive to the deterioration in different situation so the assessment and rehabilitation of concrete buildings is of important issues Assessment can be very useful for the recognition of potential damage to structures and to identify the causes of its probability. The concept of non-destructive testing (NDT) is obtaining material properties of in place specimens without the destruction of the specimen nor the structure from which is taken. Nondestructive testing (NDT) techniques can be used effectively for investigation and evaluating the actual condition of the structures. These techniques are relatively quick, easy to use and cheap and give a general indication of the required property of the concrete. This approach will enable us to find suspected zones, thereby reducing the time and cost of examining a large mass of concrete. The choice of particular NDT method depends upon the property of concrete to be observed such as strength, corrosion, crack monitoring etc.

The NDT being fast, easy to use at site and relatively less expensive can be used for,

1) Testing any number of pointes and locations,

2) Assessing the actual condition of reinforcement,

3) Main objective of assessment is to ensure that structure and its different parts do not fail under its loading condition.

4) Assessment is carried out so that its maximum resistance capacity can be observed.
5) Detecting cracks, voids, fractures, honeycombs and weak locations

6) To reduce the local damage affecting the life span of structures.

7) To remove excessive vibration which causes discomfort to mankind?

8) Scanning for reinforcement location, stress location

9) Assess overall stability of the structure

\section{LITERATURE REVIEW}

Literature survey is carried out by study of various Research paper related on Structural health monitoring and condition assessment of RC structure

Mr. Ayaz mahmood [1] In this thesis Non-destructive evaluation (NDE) methods are used for,(a) Concrete strength determination and (b) Concrete damage detection. Rebound hammer test and Ultra-sonic pulse velocity test have be done on specimens and the column, beams and slabs of two double storied buildings in NIT Rourkela. 6 Cubes were cast, targeting at different mean strengths, and then tested by rebound hammer and UPV and get Predicted compressive strength by help of Rebound numbers and Velocity. Also plot the graph between rebound number vs. compressive strength and velocity vs compressive strength. Then after M-20 and M- 25 concrete grade beam were casted. Again Rebound hammer and UPV tested on beams for comparative analysis to know the effect of reinforcement on the test Then after compare the without reinforcement and with reinforcement results, the maximum variation for Rebound value is $\mathbf{3 . 6 \%}$ where in case of Ultrasonic Pulse Velocity the maximum variation is $\mathbf{1 6 . 1 \%}$. Therefore the variations are well within the tolerable limits. Then after rebound hammer and UPV were tested on actual structure and got existing condition of the structure. 


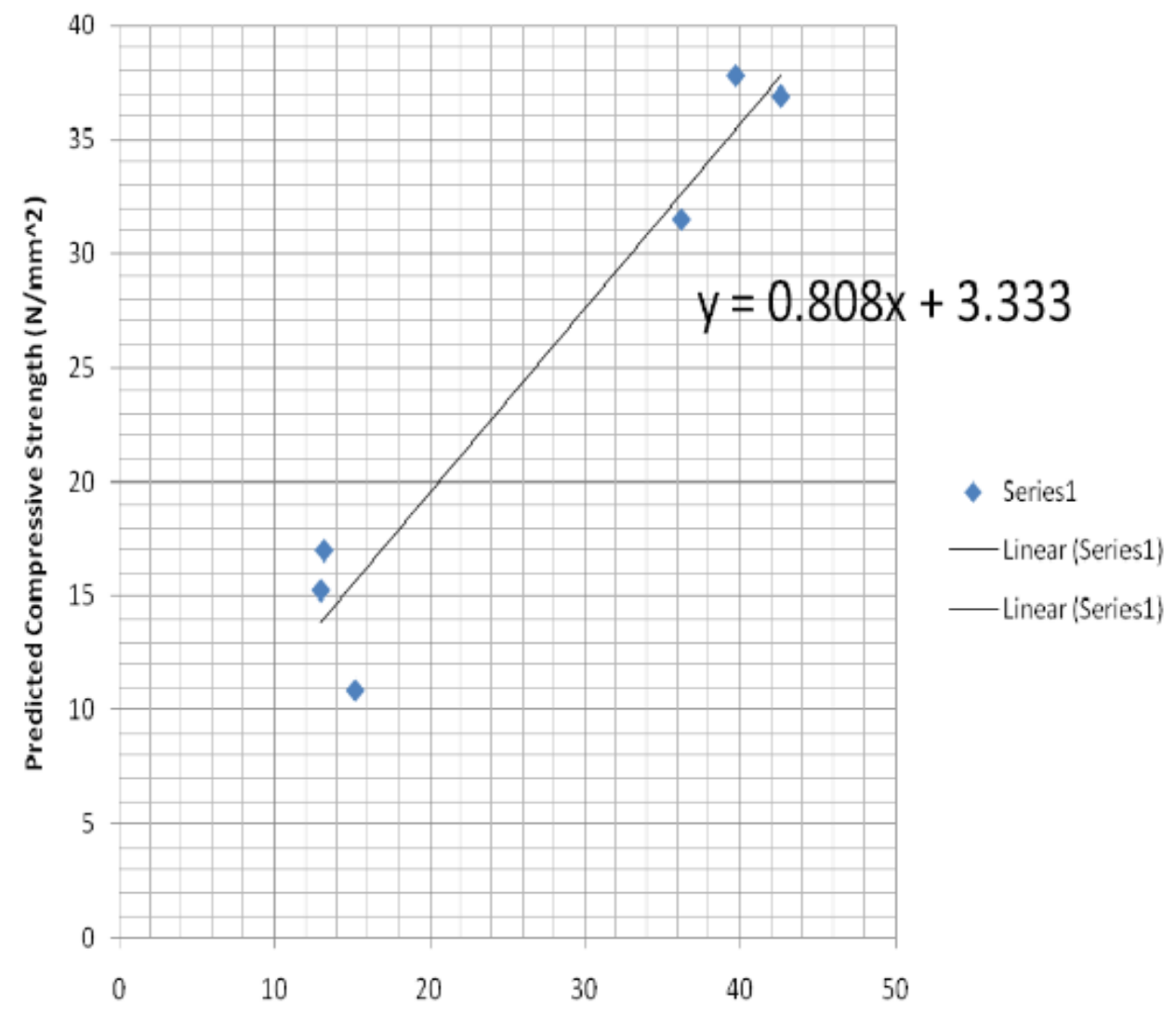

Fig 1: Calibration Graph for Rebound Hammer with its equation

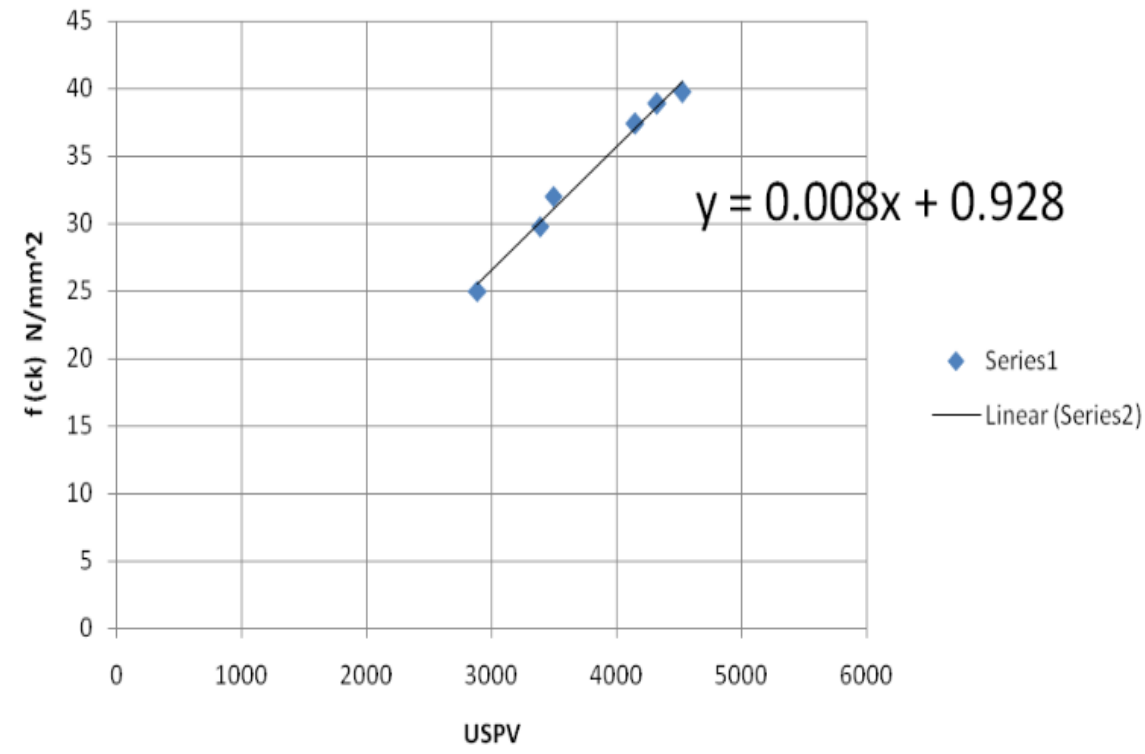

Fig 2 : Graph obtained for USPV Testing

D. Breysse [2] in this paper has been analyzes why and how nondestructive testing (NDT) measurements can be used in order to assess on site strength of concrete. It is based on (a) an in-depth critical review of existing models, (b) an analysis of experimental data gathered by many authors in laboratory studies as well as on site, (c) the development and analysis of synthetic simulations designed in order to reproduce the main patterns exhibited with real data while better controlling influencing parameters. The key factors influencing the quality of strength estimate are identified. Two NDT techniques (UPV and rebound) are prioritized and many empirical strength-NDT models are analyzed. It is shown that the measurement error has a much larger influence on the quality of estimate than the model error. The key issue of calibration is addressed and a proposal is made in the case of the SonReb combined approach. 
Ehiorobo J.O [3] in this paper authors carried out structural monitoring, periodic measurement of displacements, strains, stresses and damage evaluation (e.g. crack width) and vibration characteristics and mainly visual inspection of the structure. To detect the various crakes and also measuring the width of cracks, to show the layout of that structures. In this papers also using various non-destructive test to detect the cracks and to evaluate the existing condition of the structure. The cracks within the building vary in width from $0.75 \mathrm{~mm}$ to $31.50 \mathrm{~mm}$. As some of the cracks along the wall are more than $25 \mathrm{~mm}$, it means that the stability of the building is already being impaired.

Ha-Won Song [4] In this paper authors have focus on corrosion and have worked on detecting corrosion for different structures such as bridges, buildings and others structure locating around the coastline area. Authors also emphasize on structural Health monitoring, electrochemical techniques, durability maintenance and repair of structures. For measurement of the corrosion rate of reinforcing steel in concrete, many electrochemical and non-destructive techniques are available for monitoring corrosion of steel in concrete structures. Rebar corrosion on existing structures can be assessed by different methods such as, Visual inspection Open circuit potential (OCP) measurements,. Surface potential (SP) measurements, Concrete resistivity measurement, Galvan static pulse transient method Embeddable corrosion monitoring sensor, Cover thickness measurements, Ultrasonic pulse velocity technique, X-ray, Gamma radiography measurement, Infrared thermograph Electrochemical etc. Sensors are also used on structures exhibiting corrosion as part of a rehabilitation strategy to assess the effectiveness of repairs and to determine the future repair cycle

Katalin Szilágyi [5] Present paper introduces the SBZ-model developed by the authors of the paper which is a phenomenological constitutive model for the rebound surface hardness of concrete as a time dependent material property. The model covers the following empirical material laws: relationship between the water-cement ratio and the compressive strength of concrete at the age of 28 days; development of the concrete compressive strength in time; relationship between the compressive strength of concrete and the rebound index at the age of 28 days; the development of carbonation depth of concrete in time; the influence of carbonation depth of concrete on the rebound index.

Kumavat H.R [6] The paper present case study include the use of various Non-Destructive Test (NDT), to evaluate the concrete quality of building age was 8 years. NDT used such as Ultrasonic pulse velocity, half-cell potential, carbonation depth, rebar locator, cover meter and core sampling. Initially, the structure deteriorates due to cyclic temperature variations, physical causes and aggressive chemical attack due to the environment.
The research paper also focus on standard testing procedure of NDT and sequence of operation for obtaining accuracy as well as the problems created during the testing and the limitations of the tests are considered. In building structure it was observed that the half-cell potential reading of concrete beam is $15 \%$ more than the concrete column, the reading is shift in between $200 \mathrm{mv}$ to $500 \mathrm{mv}$. There was 50 to $75 \%$ of probability of corrosion in beam member, due to shifting towards more negative values getting chances of corrosion of reinforcement

Mhammadreza Hamidian [7] in this research paper authors used Rebound hammer test and Ultrasonic pulse velocity test on specimen and existing structure and got compressive strength of concrete and comparison along with actual compressive strength which is obtain from compressive testing machine. The structural health monitoring by NDT methods comprised of UPV and RSH (Schmidt Rebound Hammer) were carried out in laboratory and site. The experimental investigation using NDT methods showed that a good correlation exists between compressive strength, SRH and UPV. The SRH offers method of achieving concrete strength with accuracy of \pm 15 to \pm 20 parent and the UPV method is a perfect instrument for both existing structures and those under construction with accuracy within $\pm 20 \%$.

M. Torres-Luque [8] In This paper highlights the importance of chloride content measuring, and also summarizes the state of the art of non-destructive and in situ techniques for measuring chloride content into concrete structures. These techniques have been developed over the past twenty years, and they have been shown as good alternatives in durability field. They are based on three methods: electrical resistivity (ER), ion selective electrode (ISE) and optical fiber sensors (OFS).

Although other NDTs have been proposed such as electrochemical impedances spectroscopy, grounding penetrating radar and capacitive methods, until now, there is not enough results about their performance, accuracy, robustness, and chemical stability. Consequently, research efforts should focus on the improvement of the accuracy of these NDTs under in-field exposure conditions.

MR.Meltem Vatan [9] In this research paper to identify the potential seismic risk in existing historic buildings for hazard mitigation, disaster preparedness and prior knowledge of potential hazards. Seismic risk evaluation is based on safety assessment which requires qualitative and quantitative data. This data is necessary before making any intervention decision. The qualitative data is visual inspection of decays, structural damages and deteriorations; and the quantitative data requires laboratory tests, structural analysis etc. Obtaining the quantitative data is detailed method, which necessitates specialists and takes more time and money. The fact that there are so many historic buildings and a few specialists on this field it is very important to make condition survey based on visual inspection as a first step of safety assessment procedure 
Mehdi Modares [10] in this work, a new method with a hybrid experimental/analytical framework for condition assessment and life prediction of existing structures is developed. This objective hybrid framework combines experimental structural measurements (e.g., results from non-destructive tests or routine performance and/or inspection data for structure's response) and theoretical structural uncertainty analyses (interval finite element method). This method uses the structural measurements, with consideration of uncertainties, in structural uncertainty analyses, for estimating the condition of a structure. Application of structural measurement data, integrated with an enhanced structural analysis scheme, and with consideration of uncertainties provides the necessary information to make decisions regarding inspections, rehabilitation and repairs.

\section{DISCUSSION}

From the above literature it is clear that many researchers have put their efforts to study the various Non-Destructive tests on structures for concrete strength determination, concrete damage detection, to detect the corrosion in steel and also find the deflection of structure.

\section{CONCLUSION}

According to literature the researchers have been done lots of work to detect distress, deterioration and existing condition of any structures like buildings, bridges, any hydraulic structure etc. by Various NDT, using sensors and Visual inspection. NDT tests such as rebound hammer, UPV and combine of Rebound hammer and UPV are most commonly used for Health monitoring of RC Structure from the literature. Structural health monitoring is an important aspect in ensuring successful performance of a structure in its given life span. The method of conducting structural health monitoring varies highly with the type and usage of structures which needs to be investigated. Hence it is imperative that the structure which needs to be investigated must be studied thoroughly before adopting a proper strategy to conduct structural health monitoring.

\section{REFERENCES}

[1]. Mr.Ayaz Mahmood, "Structural Health Monitoring using Non-destructive testing of concrete", Department of Civil engineering -National Institute of Technology Rurkela-2008.

[2]. D. Breysse "Nondestructive evaluation of concrete strength: An historical review and a new perspective by combining NDT methods", Elsevier - 19th December 2011 [3]. Ehiorobo J.O, Izinyon O. C and Ogirigbo R.O., "Measurement and Documentation for Structural Intergrity Assessment of In-Service Building At Risk", TS07E Engineering Surveying 1 -6638, Nigeria-6th May 2013

[4]. Ha-Won Song and Velu Saraswathy, "Corrosion Monitoring of Reinforced Concrete Structures - A Review", International journal of Electrochemical of science, 1st Jun [5]. Katalin Szilágyi ,Adorján Borosnyói, István Zsigovics "Rebound surface hardness of concrete: Introduction of an empirical constitutive model", Elsevier journal-13th Nov 2010

[6]. Kumavat H.R , Tapkire Ganesh , Patil P.S, Chitte C.J “ CONDITION ASSESSMENT OF CONCRETE WITH NDT -CASE STUDY", International Journal of research in Engineering and Technology, Vol-3 special issue 09,June 14

[7]. Mhammadreza Hamidian, Ali Shariati , M.M . Arabnejad Khanouki, Hamid Sinaei, Ali Toghroli and Karim Nouri , "Application of Schmidt rebound hammer and ultrasonic pulse velocity techniques for structural health monitoring" ,Scientific Research and Essays Vol-7, 7th jun20

[8]. M. Torres-Luque , E. Bastidas-Arteaga b, F. Schoefs b, M. Sánchez-Silva a, J.F. Osma "Non-destructive methods for measuring chloride ingress into concrete:State-of-the-art and future challenges" ELSEVIER Journal- 10th jul-2014

[9]. MR.Meltem Vatan, Assis. Prof., Aydin University, Faculty of Engineering and Architecture,Istambul, Turkey, “ CONDITION SURVEY OF HISTORICAL BUILDINGS BY VISUAL INSPECTION -CASE STUDY : MURAT PASHA MOSQUE", International Journal of Electronics , Mechanical and Mechatronics engineering, vol.2 number.1, pp.147-156.

[10]. Mehdi Modares ,Shyamala Venkitaraman "Reliable condition assessment of structures using hybrid structural measurements and structural uncertainty analyses" ELSEVIER Journal- 15th March-2014

\section{BIOGRAPHIES}

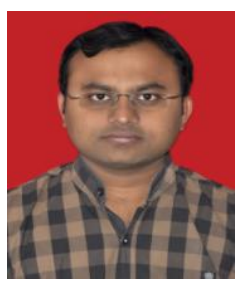

Darshakumar Vijaykumar Mehta was born in 1991 in Talaja, Gujarat. He receives his Bachelor of Engineering degree in Civil Engineering from the Grow more faculty of engineering College, Himmatnagar in 2013. At present he is Final year student of Master's degree in Structural engineering from Marwadi Education Foundation Group of Institutions, Gujarat Technological University.

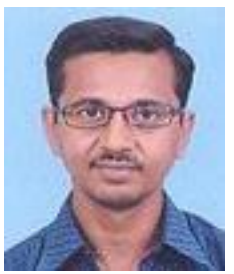

Prof. Mazhar A. Dhankot completed masters in CASAD from L. D. engineering college, Ahmedabad. Currently as an Associate Professor at Marwadi Education Foundations Group of Institute. He has an industrial and academic experience of more than 14 years. At present $\mathrm{He}$ is pursuing $\mathrm{PhD}$ in Base Isolation System. He has published about 10 papers in National and International conferences. 